\title{
Original
}

\section{Regulation of Nodal-Lefty Expression by TGF- $\beta$ Induced Pluripotent Stem (iPS) Cells Derived from Mouse Oral Mucosal Tissue}

\author{
Shoko Okada ${ }^{1)}$, Hiromi Ochiai ${ }^{1,2)}$, Akiko Saito ${ }^{1)}$, Yutaka Sato ${ }^{1)}$ and Toshifumi Azuma ${ }^{1,2)}$ \\ ${ }^{1)}$ Department of Biochemisty, Tokyo Dental College, Chiba, Japan \\ ${ }^{2}$ Oral Health Science Center hrc8,Tokyo Dental College, Chiba ,Japan \\ (Accepted for publication, July 1, 2012)
}

\begin{abstract}
Nodal-Lefty signaling is essential for embryonic stem cell pluripotency and growth control of ES cells, which play an important role in tumorigenic phenotype. We recently reported that TGF- $\beta$ increases Lefty expression in pancreatic cancer cells. However, a previous study has shown that TGF- $\beta$ is unable to induce Nodal and Lefty expression in ES or induced pluripotent stem (iPS) cells. We established an iPS cell line from mouse oral tissue via retroviral gene transfer of OCT3/4, Sox2, c-Myc and KLF4. The obtained iPS cells expressed undifferentiated markers, such as OCT4, Nanog and SSEA1. We observed induction of the Lefty gene in these iPS cells, as well as in mouse ES cells in ES medium either with or without TGF- $\beta$ treatment. This is the first report showing Lefty expression in iPS cells. We then investigated the signaling relationship between TGF- $\beta$ and mitogen-activated protein kinase (MAPK) by using specific kinase inhibitors, and found that $\mathrm{p} 38$ has some effect on Lefty expression. Taken together, these results suggest that iPS cells from oral tissue possess a different mechanism for Lefty expression than mouse ES cells. TGF- $\beta$ with p38 is able to regulate Lefty expression in iPS cells.
\end{abstract}

Key words: iPS cells, Nodal-Lefty, Regenerative therapy, TGF-beta1, Tumorigenesis

\section{Introduction}

Embryonic stem (ES) cells are multi-potent precursor cells that develop into specified cells during development, and many reports have noted that similar differential changes are similarly observed during cancer progression. Previous studies have capitalized on these similarities between tissue stem cells and cancer stem cells. ${ }^{1,2}$ Although studies have focused on the role of embryonic signals in the regulation of tumor cells, many signaling differences are still observed between cancer stem cells and embryonic stem cells and these differences may lead to new cancer treatment. ${ }^{3)}$ Nodal is a member of the TGF- $\beta$ family and the signaling pathway may act via Activin-like receptors. ${ }^{4}$ Global transcriptional profiling of ES cells grown under pluripotent and differentiating conditions have been compared. The genes that are downregulated under differentiation conditions include members of the TGF- $\beta$ signaling pathway, such as Nodal, teratomaderived growth factor-1 (Cripto) and Lefty. ${ }^{5}-{ }^{8}$ Cripto and Lefty are inhibitors of Nodal and regulate differentiation of embryos. ${ }^{9}-$ ${ }^{12)}$ A balance of activities among these factors is required for proper development, and deletion of these genes often gives rise to fatal Correspondence to: Dr. Toshifumi Azuma, Postal address: Department of Biochemistry, Tokyo Dental Collage 1-2-2, Masago, Mihama-ku, Chiba City, 261-8502, Japan. Tel: +81-43-270-3750, Fax: +81-43-270-3752, E-mail:tazuma@tdc.ac.jp phenotypes.

Another important function of Nodal signaling is cancer progression. Hendrix et al. reported that aggressive cancer cells, expressing a multi-potent, embryonic cell-like phenotype, express the embryonic morphogen Nodal. They suggested that there was a convergence between cancer cells and stem cells. Overexpression of Nodal prevents human ES cell differentiation, and inhibiting Nodal signaling in metastatic melanoma cells resulted in decreased colony formation in soft agar concomitant with marked abrogation of tumor formation. ${ }^{13)}$ The expression of Nodal in metastatic melanoma cells is significantly elevated and expressed Nodal is functional; transplantation of melanoma cells expressing Nodal give rise to an ectopic embryonic axis in zebrafish. This suggests that aggressive cancer cells possess the mechanisms used in embryonic cells and vice versa. Indeed, the embryonic microenvironment has been shown to inhibit the tumorigenicity of a variety of cancer cell lines. ${ }^{14)}$

Although Nodal and Lefty are under the control of Smad2/3 pathway, which is also known as the canonical pathway for TGF$\beta$, a previous paper suggested that TGF- $\beta$ signaling is inhibited by Lefty, and reported that Lefty provides a repressed state for TGF-b-responsive genes, and that it participates in negative modulation of TGF- $\beta .{ }^{15-17)}$ 
We recently showed that in some cancer cell lines, TGF-â induces marked expression of Lefty, and that this is regulated by the MAPK pathway. We were able to induce Lefty expression at levels greater than 50-fold in pancreatic cancer cells (PANC-1) by treatment with TGF-â and MAPK inhibitors. ${ }^{18)}$ Lefty is strongly expressed in human ES cells, while substantial reductions in Lefty expression are seen in the embryonic body. It is interesting that a marked decrease in Lefty is observed in hiPSCs, as compared with hESCs. Thus, even though there have been no previous reports showing how mouse Lefty gene expression is regulated, it is possible that some differences may be observed in Lefty gene expression in mouse ES and iPS cells.

These observations suggest that Lefty expression in mouse iPS cells, which have been shown to be more tumorigenic than mouse ES cells, is under the control of different mechanisms that in human ES cells. It would be of interest to investigate whether TGF- $\beta$ controls Lefty expression in mouse iPS cells, although global gene profiling was negative in mouse ES cells.

Here, we showed that iPS cells, which were established from mouse oral tissue, express the Lefty gene after TGF- $\beta$ treatment. In addition, this induction of the Lefty gene requires $\mathrm{P} 38$ activation, as P38 inhibitor treatment significantly decreased lefty expression

\section{Materials and Methods}

\section{Cell culture}

The mouse oral mucosa cell line was established from 6-weekold female Balb/c mice. Excised buccal mucosal tissue was submerged three times in PBS solution containing $50 \mathrm{IU} / \mathrm{ml}$ penicillin-streptomycin and $5 \mu \mathrm{g} / \mathrm{ml}$ amphotericin B for $10 \mathrm{~min}$ at room temperature. After explants were incubated at $37^{\circ} \mathrm{C}$ for $1 \mathrm{~h}$ with $3 \mathrm{mg} / \mathrm{ml}$ dispase II (Roche Diagnostics, Basel, Switzerland), the epithelial cell sheet was removed from the mesenchymal tissue, followed by treatment with $0.25 \%$ trypsin-EDTA solution for 15 min at room temperature to separate the cells. Cells were then filtered through a $0.22 \mu \mathrm{m}$ filter (Millipore, MA,USA) and were collected by centrifugation $\left(2000 \mathrm{rpm}\right.$ for $5 \mathrm{~min}$ at $4^{\circ} \mathrm{C}$ ) and resuspended in fresh medium. Cells were cultured in DMEM supplemented with $10 \%$ fetal bovine serum (FBS) (Life Thechnology, CA,USA) and $1 \%$ penicillin-streptomycin (Life Thechnology).

ES cell line Strain 129/SVEN, (Millipore) and OM - iPS cell lines were maintained on feeder layers of mitomycin C-treated mouse embryonic fibroblasts (MEFs) in conditional medium (CM), comprising Dulbecco's modified eagle's medium (DMEM; Invitrogen, Carlsbad, CA) supplemented with $15 \%$ knockout serum replacement (Life Thechnology), $1 \%$ non-essential amino acids (Millipore), $100 \mu \mathrm{M}$ 2-mercaptoethanol (Millipore), $1 \%$ Retrovirus production

Platinum-E retroviral packaging (Plat-E) cells (Cell Biolabs,
Inc., San Diego, CA) were seeded at $7 \times 10^{6}$ cells/100-mm dish and cultured overnight. The next day, Moloney murine leukemia virus (MMLV)-based retroviral vector (pMXs-IRES-puro) containing the open reading frames of c-Myc, Oct3/4, Sox2, Klf4 and DsRed-Express (Addgene, Cambridge, MA) were transfected into Plat-E cells with the FuGENE HD Transfection Reagent (Roche Diagnostics), in accordance with the manufacturer's instructions. Viral supernatants were collected at $48 \mathrm{~h}$ posttransfection, and were then filtered through a $0.45-\mu \mathrm{m}$ filter (Millipore) and supplemented with $4 \mu \mathrm{g} / \mathrm{ml}$ polybrene (Sigma). Target cells were transduced with c-Myc:Oct3/4:Sox2:Klf4:DsRed at a 1:1:1:1:3 mixture of viral supernatant. Transduction efficiency was monitored by evaluation of DsRed expression under a fluorescence microscope.

\section{Reprogramming of mouse oral mucosa (OM) cells}

Reprogramming was performed as described previously. ${ }^{19,20)}$ Briefly, OM cells were seeded into the wells $\left(1 \times 10^{5}\right.$ cells /well $)$ of 6-well plates, and were cultured in DMEM with $10 \%$ FBS and $1 \%$ penicillin-streptomycin at $37^{\circ} \mathrm{C}$ with $5 \% \mathrm{CO}_{2}$ for $24 \mathrm{~h}$. The next day, cells were infected with viral supernatant for $24 \mathrm{~h}$, and were then replaced with fresh DMEM containing $10 \%$ FBS. At 4 days post-infection, infected cells were reseeded at $5 \times 10^{4}$ cells/ 100-mm dish on mitomycin C-inactivated MEF feeder cells. The following day, medium was replaced with mouse ES cell medium and refreshed every 2 days until ES cell-like colonies emerged (on average, less than 3 weeks). iPS colonies were selected based on mouse ES cell-like colony morphology, and medium was changed every day. Selected colonies were subsequently expanded and maintained on MEFs feeder cells in mouse ES cell medium.

\section{Immunohistochemical staining of undifferentiated cells}

Cells were fixed with PBS containing $4 \%$ paraformaldehyde for $10 \mathrm{~min}$ at room temperature. After washing with PBS, cells were treated with PBS containing 0.1\% Triton X-100 for 10 min and then $1 \%$ bovine serum albumin (BSA; Sigma) for $30 \mathrm{~min}$ at room temperature. Primary antibodies included stage-specific embryonic antigen SSEA-1 ( Santa Cruz, Santa Cruz, CA, USA), OCT3/4 ( CST, , MA, USA) and NANOG ( Abcam, Cambridge, $\mathrm{UK})$.

\section{Immunohistochemical staining of pluripotent cells}

OM-iPS cells were cultured for 7 days without replating, we observed cells developing ball-shaped morphology, known as embryonic bodies (EBs). EBs were transferred onto gelatin-coated dishes, and culture was continued for another week. Immunohistochemical observations were performed to detect $\beta$ III tubulin (marker of ectoderm; CST), $\alpha 1$-fetoprotein (AFP) (marker of endoderm; 1:50; R\&D, MN,USA) and $\alpha$-smooth muscle action ( $\alpha$-SMA) (marker of mesoderm; Abcam) 
Shoko Okada et al.: Regulation of Nodal-Lefty Expression by TGF- $\beta$ in m- iPS cell
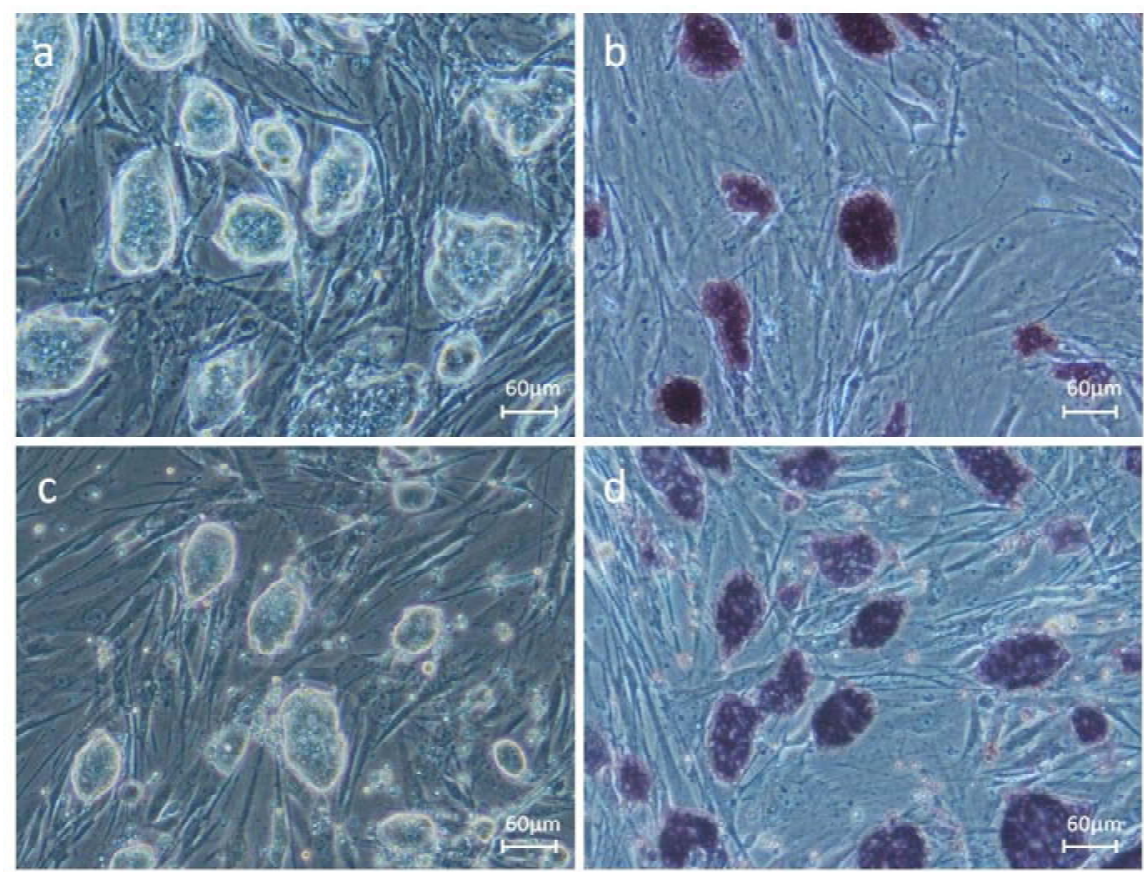

Figure 1: Morphology of mouse ES cells and mouse oral mucosal tissue - induced pluripotent stem (OM-iPS) cells. ES cell-like colonies from mouse oral mucosal tissue is collected and passaged manually. a, phase contrast of mouse ES cell $(\times 100)$. b, ALP staining of mouse ES cell $(\times 100)$.c, phase contrast of OM - iPS cells $(\times 100)$. d, ALP staining of OM - iPS cell $(\times 100)$.
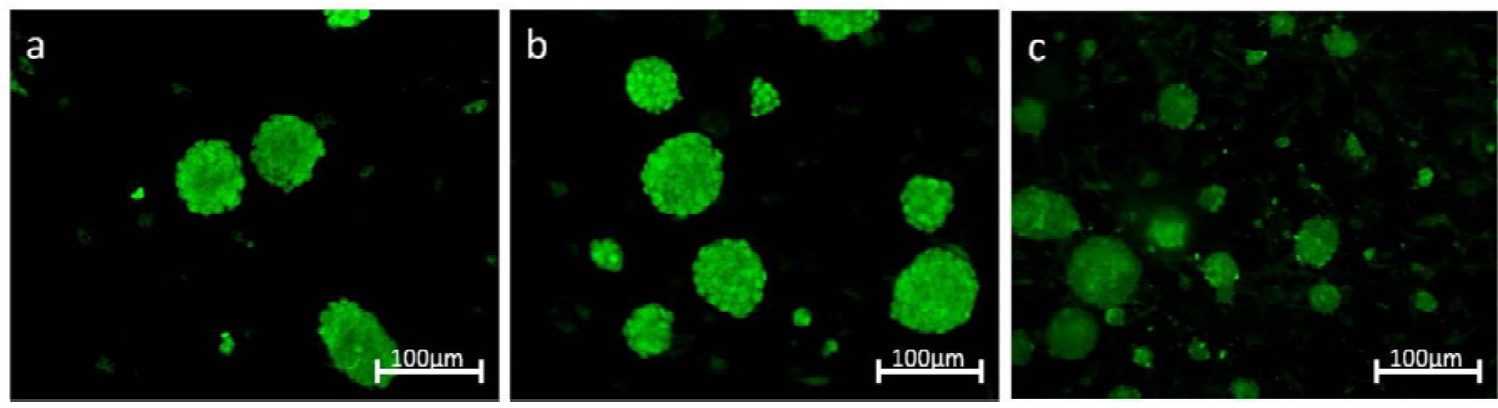

Figure 2. Characterization of OM - iPS cells. To confirm that the cells from the putative colonies were iPS cells, we examined the mouse ES cell markers by immunofluorescence. OM - iPS cells was stained with antibodies against proteins associated with the mouse ES cells Nanog(a), Oct3/4(b) and SSEA1 (c) and are shown as green fluorescence, respectively ( $\times 200)$.

\section{Assay for alkaline phosphatase (ALP) activity}

Cells were washed twice with PBS, fixed with $4 \%$ paraformaldehyde for $5 \mathrm{~min}$ at room temperature. Cells were rinsed twice with PBS and ALP activity was detected by incubating cells with ALP substrate solution; 5-bromo-4-chloro-3'indolyphosphate and nitro-blue tetrazolium, BCIP/NBT solution (Roche Diagnostics) at room temperature for $30 \mathrm{~min}$. After washing cells with distilled water three times, images were captured with a phase-contrast microscope.

\section{RNA isolation and quantitative real-time PCR (qRT-PCR)}

Total RNA was extracted from cultured cells using QIAzol reagent (Qiagen Inc., Valencia, CA) in accordance with the manufacturer's instructions. cDNA was synthesized using a high- capacity cDNA reverse transcription kit (Applied Biosystems, Foster City, CA). qRT-PCR analysis was performed using Premix Ex Taq ${ }^{\mathrm{TM}}$ reagent (Takara Bio Inc., Shiga, Japan) in accordance with the manufacturer's instructions. Target genes were ACAATTGCCTTGAGC for Lefty; CCAACCATGCCTACATCC A and CACAGCACGTGGAAGGAAC for Nodal; and TGTCCG TCGTGGATCTGACand CCTGCTTCACCACCTTCTTG for GAPDH.

\section{Statistical analysis}

Statistical analysis was carried out using SPSS ${ }^{\circledR}$ software (SPSS, Chicago, IL). All data are expressed as means \pm S.E. When ANOVA indicated differences among the groups, multiple comparisons between each experimental group were performed using the 


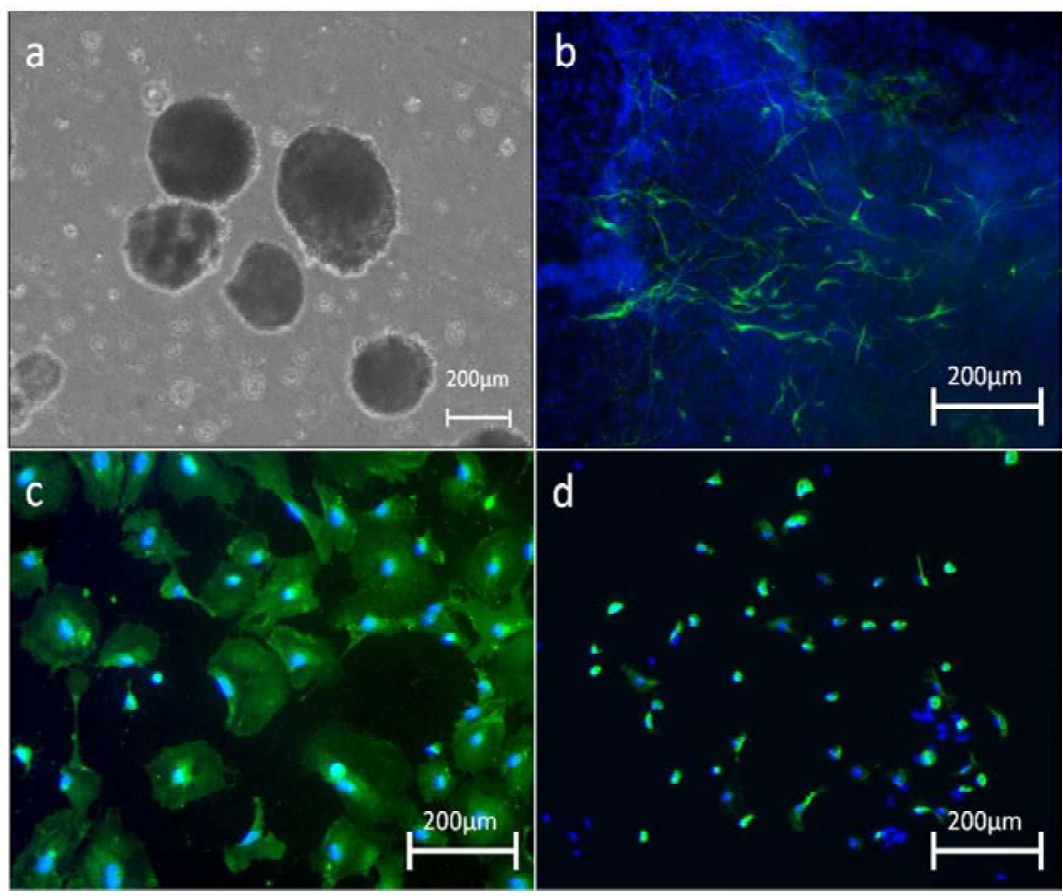

Figure 3. In vitro differentiation of OM-iPS cells. To examine the differentiation potential of OM-iPS cells, we performed floating culture to demonstrate embryoid body formation. After 7 days of floating culture, iPS cells formed embryoid bodies seen as sphere structures. These embryoid bodies were transferred onto gelatin-coated plates for another 7 days to induce spontaneous differentiation. The cells attached to the culture dish showed various types of cell morphologies. a, EB formation of iPS cells $(\times 40) \mathrm{b}$-d, immunofluorescence for $\beta$-III tubulin as a marker for ectoderm (b), $\alpha$-smooth muscle actin ( $\alpha$ SMA) as a marker for mesoderm (c), and AFP as a marker for endoderm $(d)(\times 100)$.

Bonferroni test. Statistical significance was defined as $\mathrm{p}<0.01$.

\section{Results}

We investigated the expression of ES cell markers. ES cell-like colonies began emerging on the feeder layer at 20 to 24 days after gene transduction (Fig. 1a), and 6 ES cell-like clones were isolated. Representative clones are shown in Fig. 1a and 1c.

Mouse ES cells and the 6 clones cells noted above were examined for ES cell marker expression. All clones, as well as ES cells, showed strong alkaline phosphatase (ALP) activity (Fig. $1 \mathrm{~b}, \mathrm{~d})$. Immunohistochemical analysis revealed that all cells we examined expressed mouse ES cell-specific transcriptional factors, such as Nanog, SSEA-1 and Oct3/4 (Fig. 2).

\section{In vitro $E B$ analysis}

EB formation allows iPS cells to differentiate into various cell types. We first examined the genes in cells representing all 3 germ layer EBs from OM-iPS cells, as shown in Fig. 3a. As shown in Fig. 3b-d, immunohistochemical study was performed and confirmed the expression of all 3 representative genes. Thus, we confirmed that the 6 reprogrammed cells could form EBs, and that these EBs contained different cell types, as well as AFP, $\beta$ SMA and $\beta$ III-tubulin. According to our results we isolated reprogrammed cells called iPS cells and these reprogrammed cells have the potential to differentiate into 3 different germ layers.

\section{Nodal-Lefty expression in ES and OM-iPS cells was induced by TGF- $\beta$}

As shown in Fig. 4, we investigated Nodal and Lefty expression, which is known to be strong in human ES cells. We observed no significant differences in the expression of Nodal genes with or without MAPK inhibitors. We did not observe significant changes in Lefty gene expression, except with p38 inhibitor treatment in ES cells. Our results indicated that MAPK inhibitors decreased Nodal expressions both ES cells and iPS cells, but failed to show any significant changes.

We found that addition of TGF- $\beta$ increased Lefty expression only in OM-iPS cells. We did not see any indication of upregulation of Nodal gene expression in ES cells. We found that Lefty expression in OM-iPS cell increased dose-dependently on TGF- $\beta$ addition. We did not see any significant changes with or without TGF- $\beta$. MAPK inhibitors altered Nodal gene expression, irrespective of TGF- $\beta$ addition.

Progress in iPS cell technology has opened new avenues in the development of cell therapies for regenerative medicine. Oral tissue has several advantages over dermal fibroblasts, which are a common source for iPS cells. Thus, it is of particular interest whether iPS cells from oral tissue are less tumorigenic. 
Shoko Okada et al.: Regulation of Nodal-Lefty Expression by TGF- $\beta$ in m- iPS cell
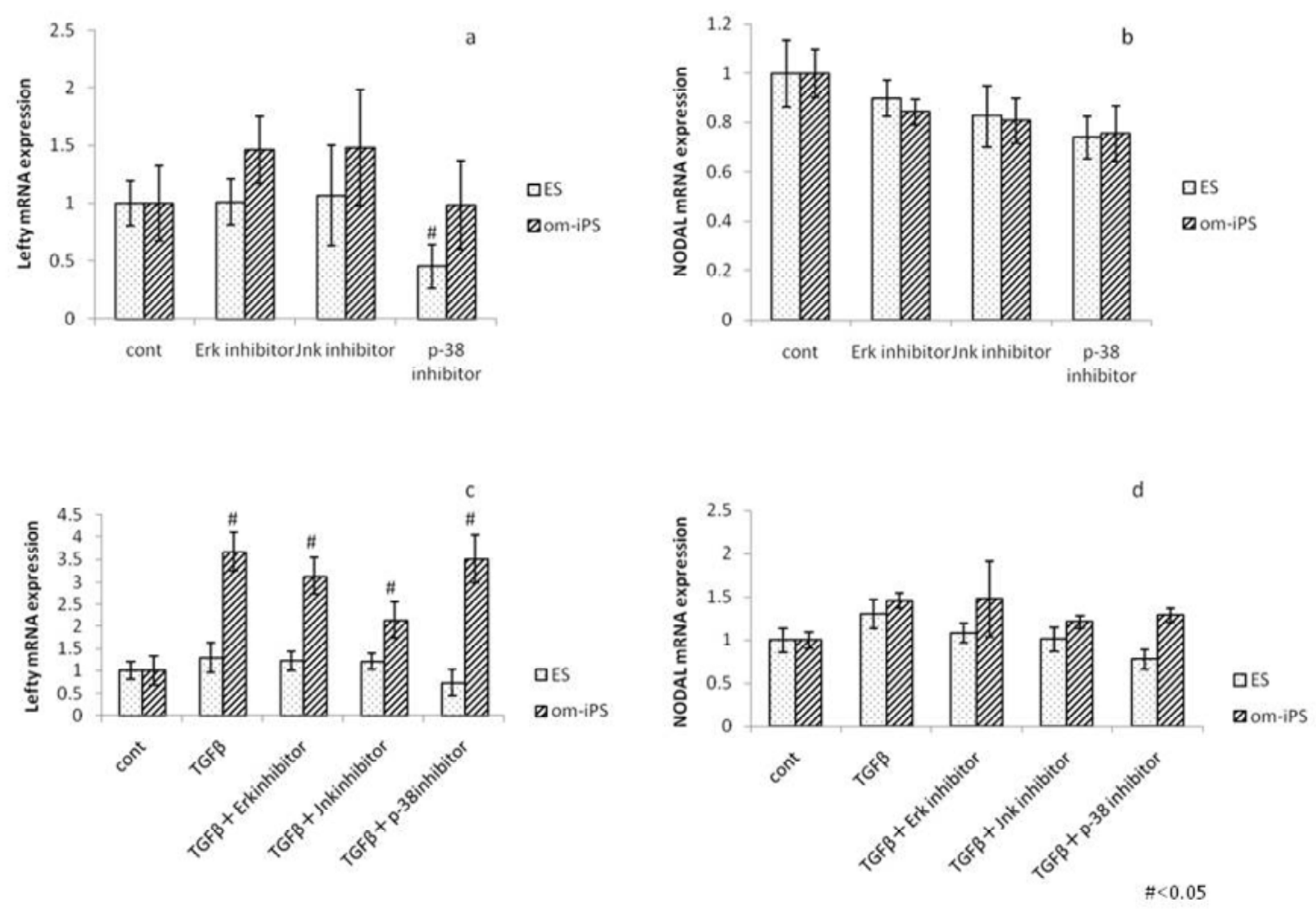

Figure 4. Nodal-Lefty expression in ES and OM- iPS cells. Real-time RT-PCR analysis of Nodal (b,d)and Lefty(a,c) gene expression in ES and OM- iPS cells. a,b, Lefty and Nodal expression treated with or without MAPK inhibitor (Erk inhibitor (10ìM), Jnk inhibitor (10ìM), and p38 inhibitor (10ìM)). c,d, Lefty and Nodal expression treated with or without TGFâ (10ng/ml) and MAPK inhibitor. The data are expressed as mean \pm standard deviation of experiments. Statistical significance was defined as $\mathrm{p}<0.01$.

Nodal, a counter part of Lefty is a essential molecule for maintaining ES stemness as well as cell differentiation. ${ }^{21)}$ Nodal expression in human ES cell was examined and revealed that Activin/Smad cascade plays an important role. Human Lefty gene expression was regulated by Activin/Nodal. But it has been suggested that Nodal-Lefty gene expression might have distinct expression system from species to species. Another important fact of Nodal-Lefty was close association with cancer biology. It was reported that melanoma cells with high expression of Nodal expression is aggressive and ES medium containing Lefty secreted from ES cells could attenuate their aggressiveness. Thus Lefty is a recognized as tumor suppressor and Nodal inhibitor expressed in ES cells. These proteins are member of TGF- $\beta$ superfamily and regulate ES cell pluripotency, left-right asymmetry and tumor progression. It has been reported that human-ES cells express Lefty at high levels, but that human iPS cells express slightly less Lefty than human ES. ${ }^{22)}$ Another interesting observation is that the expression patterns and regulation of human Lefty genes differ from those of mouse Lefty genes, even though there is no doubt that both the mouse and human Lefty gene play an important role in development and differentiation. Hamada et al. reported that both mouse and human Lefty protein inhibit Nodal signaling, although the transcriptional regulatory mechanisms of the human Lefty gene are distinct from those of the mouse Lefty gene. ${ }^{23)}$
This report is the first to show TGF- $\beta$-induced Lefty expression in mouse iPS cells.

We recently reported that Lefty expression was not present in pancreatic cancer cells, while TGF- $\beta$ markedly induced its expression. Furthermore, MAPK inhibition enhances Lefty expression. According to previous reports, only Activin and Smad2/3 activation is required for Lefty expression in human ES cells and TGF- $\beta$ regulation of Lefty expression in mouse ES cells has not been reported. Nodal and inhibitors of Nodal signaling, such as Lefty-A and Lefty-B (human Lefty), are downregulated very early in the differentiation of human ES. High expression of these genes in undifferentiated cells is maintained by activation of the transcription factor $\operatorname{Smad} 2 / 3$, downstream of the Activinlinked kinase (ALK) 4/5/7. Treatment of differentiating cells with Activin A leads to activation of $\operatorname{Smad} 2 / 3$ and expression of Nodal and Lefty, while inhibition of ALK4/5/7 by the kinase inhibitor SB-431542 blocks activation of $\operatorname{Smad} 2 / 3$ and expression of these genes in the undifferentiated state. ${ }^{24)}$ However, these results were not observed in mouse ES cells.

The roles of TGF- $\beta$ superfamily members in ES cell, selfrenewal and differentiation described above, have highlight the fact that, despite their fundamental similarities, there appear to be significant differences between mouse and human ES cells. For example, bone morphogenetic protein (BMP) signals have been 
shown in combination with leukemia inhibitory factor (LIF) to maintain mouse ES cells in an undifferentiated, pluripotent state. In contrast, human ES cells can only maintain an undifferentiated phenotype by suppression of endogenous BMP signaling. Another important aspect of Lefty gene regulation was reported by Hendrix et al. They showed that Lefty gene expression was substantially lower in human iPS when compared with human ES cells. ${ }^{25}$ )

This difference may be related to the tumorigenic capacity of iPS. We found that although TGF- $\beta$ treatment failed to increase Lefty expression in mouse ES cells, we observed increases in Lefty expression in mouse OM-iPS cells. We also observed increases in Lefty expression in human iPS cells from the Riken cell bank (unpublished data). Taken together, these results indicate that mouse ES cells and iPS cells have different regulatory mechanisms for Lefty.

These differences could give rise to differences in left-right asymmetry from species to species. It is known that the pluripotency of iPS cells is due to several factors, which may invoke the capacity of TGF- $\beta$ superfamily ligands to act as morphogens, as morphogens are known to exert different effects at different concentrations, including variability in activity levels, delivery mechanisms and experimental systems. The other possibilities are related to clonal differences in iPS cells. As Lefty expression is rapidly downregulated at very early stages of development, it is possible that the iPS cells we produced were not as immature as ES cells. Nonetheless, it is surprising that ES and iPS cells have different responses to TGF- $\beta$ superfamily members.

The TGF- $\beta$ signaling pathway is involved in a wide range of cellular processes, and is therefore very heavily regulated. MAPK is a major signaling pathway that controls various biological functions. It is known that MAPK signaling negatively regulates TGF- $\beta$ signaling pathways in both canonical and non-canonical pathways in epithelial cells, while positively regulating these pathways in mesenchymal cells. We found that TGF- $\beta$ significantly up-regulates Lefty expression in pancreatic cancer cells. In pancreatic cancer cells, we found that ras-mutation and subsequent MAPK activation negatively regulates Lefty expression. Thus, we investigated whether Lefty expression induced by TGF- $\beta$ is regulated by MAPKs in OM-iPS cells. Unlike pancreatic cancer cells, we found that $\mathrm{p} 38$ inhibition revealed some positive effects on TGF- $\beta$-induced Lefty expression. It is also interesting to observe the differences in regulatory mechanisms for Lefty expression in mouse ES cells, iPS cells, human ES cells and human iPS cells.

In conclusion, we produced iPS cells from mouse oral tissue. We found that these iPS cells have distinct regulatory mechanisms for Lefty expression induced by TGF- $\beta$, which increases Lefty expression in OM-iPS cells. TGF- $\beta$ may play a role in pluripotency through Lefty expression, as Nodal-Lefty signaling is a key pathway for ES and iPS cell differentiation.

\section{Acknowledgments}

This study was supported by a grant from the Oral Health Science Center hrc7 project of Tokyo Dental College, and by a "High-Tech Research Center" Project for Private Universities matching fund subsidy from the Ministry of Education, Culture, Sports, Science and Technology (MEXT) of Japan, 2010-2012.

\section{References}

1. Minchiotti G. Nodal-dependant Cripto signaling in ES cells. Oncogene 37: 5668-5675, 2005

2. Saloman DS, Bianco C, Ebert AD, Khan NI, De Santis M, Normanno N, Wechselberger C, Seno M, Williams K, Sanicola M, Foley S, Gullick WJ and Persico G. The EGFCFC family. Endocr Relat Cancer 4: 199-226, 2000

3. Clarke MF and Fuller M. Stem cells and cancer: Two faces of eve. Cell 6: 1111-1115, 2006

4. Kumar A, Novoselov V, Celeste AJ, Wolfman NM, ten Dijke P and Kuehn MR.Nodal signaling uses activin and transforming growth factor-beta receptor-regulated Smads. J Biol Chem 1: 656-661, 2001

5. Meno C, Saijoh Y, Fujii H, Ikeda M, Yokoyama T, Yokoyama M, Toyoda Y and Hamada H.Left-right asymmetric expression of the TGF beta-family member lefty in mouse embryos. Nature 6578: 151-155, 1996

6. Raya A and Izpisúa Belmonte JC. Left-right asymmetry in the vertebrate embryo: from early information to higher-level integration. Nat Rev Genet 4: 283-293, 2006

7. Saijoh Y, Adachi H, Sakuma R, Yeo CY, Yashiro K, Watanabe M, Hashiguchi H, Mochida K, Ohishi S, Kawabata M, Miyazono K, Whitman M and Hamada H. Left-right asymmetric expression of lefty 2 and nodal is induced by a signaling pathway that includes the transcription factor FAST2. Mol Cell 1: 35-47, 2000

8. Besser D.Expression of Nodal, Lefty-A and Lefty-B in undifferentiated human embryonic stem cells requires activation of Smad2/3. J Biol Chem 43: 45076-45084, 2004

9. Cheng SK, Olale F, Brivanlou AH and Schier AF. Lefty blocks a subset of TGFbeta signals by antagonizing EGFCFC coreceptors. PLoS Biol 2: E30, 2004

10. Meno C, Gritsman K, Ohishi S, Ohfuji Y, Heckscher E, Mochida K, Shimono A, Kondoh H, Talbot WS, Robertson EJ, Schier AF and Hamada H. Mouse Lefty2 and zebrafish antivin are feedback inhibitors of nodal signaling during vertebrate gastrulation. Mol Cell 3: 287-298, 1999

11. Sakuma R, Ohnishi Yi Y, Meno C, Fujii H, Juan H, Takeuchi J, Ogura T, Li E, Miyazono K and Hamada H. Inhibition of Nodal signalling by Lefty mediated through interaction with 
Shoko Okada et al.: Regulation of Nodal-Lefty Expression by TGF- $\beta$ in m- iPS cell

common receptors and efficient diffusion. Genes Cells 4: 401-412, 2002

12. Tabibzadeh $\mathrm{S}$ and Hemmati-Brivanlou A. Lefty at the crossroads of (stemness) and differentiative events. Stem Cells 9: 1998-2006, 2006

13. Topczewska JM, Postovit LM, Margaryan NV, Sam A, Hess AR, Wheaton WW, Nickoloff BJ, Topczewski J and Hendrix MJ. Embryonic and tumorigenic pathways converge via Nodal signaling: role in melanoma aggressiveness. Nat Med 8: 925-932, 2006

14. Postovit LM, Margaryan NV, Seftor EA, Kirschmann DA, Lipavsky A, Wheaton WW, Abbott DE, Seftor RE and Hendrix MJ. Human embryonic stem cell microenvironment suppresses the tumorigenic phenotype of aggressive cancer cells. Proc Natl Acad Sci USA 11: 4329-4334, 2008

15. Schier AF. Nodal Morphogens. Cold Spring Harb Perspect Biol 5: a003459, 2009

16. Chen $\mathrm{C}$ and Shen MM. Two modes by which Lefty proteins inhibit nodal signaling. Curr Biol 7: 618-624, 2004

17. Schier AF. Nodal signaling in vertebrate development. Annu Rev Cell Dev Biol 19: 589-621, 2003

18. Miyata N, Azuma T, Hozawa S, Higuchi H, Yokoyama A, Kabashima A, Igarashi T, Saeki K and Hibi T. Transforming Growth factor $\beta$ and Ras/MEK/ERK signaling regulate the expression level of a novel tumor suppressor lefty. rancreas 5: 745-752, 2012

19. Egusa H, Okita K, Kayashima H, Yu G, Fukuyasu S, Saeki
M, Matsumoto T, Yamanaka S and Yatani H. Gingival fibroblasts as a promising source of induced pluripotent stem cells. PLoS One 9: e12743, 2010

20. Takahashi K, Okita K, Nakagawa M and Yamanaka S. Induction of pluripotent stem cells from fibroblast cultures. Nat Protoc 12: 3081-3089, 2007

21. Vallier L, Mendjan S, Brown S, Chng Z, Teo A, Smithers LE, Trotter MW, Cho CH, Martinez A, Rugg-Gunn P, Brons $\mathrm{G}$ and Pedersen RA. Activin/Nodal signalling maintains pluripotency by controlling Nanog expression. Development 8: 1339-1349, 2009

22. Malchenko S, Galat V, Seftor EA, Vanin EF, Costa FF, Seftor RE, Soares MB and Hendrix MJ. Cancer hallmarks in induced pluripotent cells: new insights. J Cell Physiol 2: 390-393, 2010

23. Yashiro K, Saijoh Y, Sakuma R, Tada M, Tomita N, Amano K, Matsuda Y, Monden M, Okada S and Hamada H. Distinct transcriptional regulation and phylogenetic divergence of human LEFTY genes. Genes Cells 5: 343-357, 2000

24. Ogawa K, Saito A, Matsui H, Suzuki H, Ohtsuka S, Shimosato D, Morishita Y, Watabe T, Niwa H and Miyazono K. ActivinNodal signaling is involved in propagation of mouse embryonic stem cells. J Cell Sci Pt 1: 55-65, 2007

25. Costa FF, Seftor EA, Bischof JM, Kirschmann DA, Strizzi L, Arndt K, Bonaldo Mde F, Soares MB and Hendrix MJ. Epigenetically reprogramming metastatic tumor cells with an embryonic microenvironment. Epigenomics 2: 387-398, 2009 
J.Hard Tissue Biology Vol. 21(4):391-398, 2012 
